\title{
Article
}

\section{Science in brief: Highlights from the biomechanics and physiotherapy abstracts at the International Conference on Equine Exercise Physiology.}

Hobbs, Sarah Jane

Available at http://clok.uclan.ac.uk/12535/

Hobbs, Sarah Jane ORCID: 0000-0002-1552-8647 (2015) Science in brief: Highlights from the biomechanics and physiotherapy abstracts at the International Conference on Equine Exercise Physiology. Equine Veterinary Journal, 47 (1). pp. 10-13. ISSN 0425-1644

It is advisable to refer to the publisher's version if you intend to cite from the work. http://dx.doi.org/10.1111/evj.12347

For more information about UCLan's research in this area go to http://www.uclan.ac.uk/researchgroups/ and search for <name of research Group>.

For information about Research generally at UCLan please go to http://www.uclan.ac.uk/research/

All outputs in CLoK are protected by Intellectual Property Rights law, including Copyright law. Copyright, IPR and Moral Rights for the works on this site are retained by the individual authors and/or other copyright owners. Terms and conditions for use of this material are defined in the policies page. 
1 Science in brief: Highlights from the biomechanics and physiotherapy

2 abstracts at ICEEP

3 Dr Sarah Jane Hobbs ${ }^{1^{*}}$

${ }^{1}$ Centre for Applied Sport and Exercise Sciences, University of Central Lancashire, Preston, UK.

* Corresponding Author:

Dr Sarah Jane Hobbs, Centre for Applied Sport and Exercise Sciences, University of Central Lancashire, Darwin Building 201, Preston, PR1 2HE, UK.

Tel: +441772893328

E-mail: sjhobbs1@uclan.ac.uk

Word count: 5140 (including references), 3472 (not including references)

Key words: horse, biomechanics, rehabilitation, exercise, performance, injury, hoof 
5 Although human observations of equine locomotion are as old as our relationship with the

6 horse, today’s scientists still have much to learn about horse-human interactions. Two

7 approaches are commonly used to study equine biomechanics and both were evident in

8 abstracts presented at the International Conference on Equine Exercise Physiology (ICEEP)

9 2014. One approach is to use simplified methods of measurement and analysis that provide

10 simple but meaningful objective information that can ultimately be used by the clinician or practitioner. Alternatively, more complex equipment and techniques may be used to provide detailed structural and functional information that directly measure or infer loading on the equine musculoskeletal system. Whichever methods are used it is important that they are reliable and robust, and that the errors and limitations of the measurement system are fully recognized when interpreting data. In his keynote speech, Professor Rene Van Weeren proposed that the biomechanical techniques available to scientists today provide a gateway towards a better understanding of the horse-rider interaction that must ultimately improve equine welfare whilst maintaining peak performance. The abstracts presented in this review therefore cover key topics that are relevant to welfare and performance; lameness and asymmetry, locomotion and sports performance, a focus on the axial system, and the foot.

\section{Lameness and asymmetry}

The subtleties of pathological low grade lameness compared to asymmetries that result from other causes including mechanical asymmetries, laterality, asymmetric posture, muscular imbalances, the task involved, such as circling, and the horse-human interaction was a key topic of interest. The studies presented enhanced current knowledge of kinetic, kinematic and postural asymmetries, which at times rejected long held anecdotal assumptions and undoubtedly will lead to improvements in clinical examination and diagnosis over time. 
Two studies investigated the effect of side-handling, as leading from the left is often implicated in relation to asymmetric movement and loading patterns. Head and pelvis movement symmetry was not found to be influenced by the side from which a horse was led, provided the horses had a consistent head carriage and minimum of 27 strides were used in the analysis [1]. Using a pressure plate with a smaller number of repeats over two data collection sessions no significant differences were found peak vertical force or vertical impulse with the handler on the left compared to the right [2]. Both studies therefore confirmed that side-handling can be discounted as a cause of asymmetry during lameness assessments.

Other aspects of current clinical practice were investigated in relation to subjective and objective quantification of lameness. An objective evaluation of pelvic symmetry before and after diagnostic analgesia in the hindlimb of lame horses was performed to determine which parameters changed most consistently between horses [3]. Movement amplitude between left and right tuber coxae changed consistently. Although this was not as sensitive as the difference in upward movement between left and right tuber coxae, it was considered easier to perceive in a lameness examination, so was considered the objective measurement of choice to compliment subjective assessment. The anecdotal link between tail deviation and lameness was also explored [4]. $87.2 \%$ of the horses, which included both sound and lame horses, showed some degree of tail deviation. Due to the high proportion of horses with a tail deviation and the variability in postural angle between horses, no significant relationship between tail carriage and lameness was identified. Tail deviation should therefore not be considered an indicator for lameness. 
54 Examination of the lame horse often extends beyond straight line motion on a flat surface and can include inclines, declines or circles to further investigate the origin of lameness. In relation to slopes, declines were found to increase longitudinal breaking force and maximal vertical force in the forelimb, whereas inclines increased propulsive force [5]. The demands on the superficial digital flexor tendon may therefore be greater on declines whereas the demands on the deep digital flexor tendon may be greater on inclines.

Circular motion poses additional challenges in relation to lameness diagnosis, as circle dependent movement patterns are evident and these can vary between horses. In one study [6] inter- and intra-rater agreement of lame limb identification between equine practitioners was evaluated from videos of sound and lame horses during lungeing. High inter-observer variation was found, although agreement increased by11\% greater in when evaluating forelimb compared to hindlimb lameness. To address this very problem, another study [7] compared objective classification of lameness on the circle to the exact fore-/hindlimb(s) scored lame subjectively, final diagnosis and objective classification on a straight line. The study reported a high frequency of false positives in objective classification on a circle compared to subjective evaluation, and objective measurements of asymmetry during circular motion were not associated with baseline lameness. Subtle lameness may be detectable more successfully using this technique once predictive values of circle dependent asymmetry are determined, ensuring that circle size [8] and speed are taken into account.

Circle dependent asymmetries occur due to the change in locomotion requirements, which include the production of centripetal force at the ground to make the turn. Centripetal force can be produced by leaning inwards, which shifts the point of application of the ground reaction force towards the centre of the circle [9]. This medio-lateral loading is borne by the 
forelimbs in a proportion that is directly related to their greater support of the body mass against gravity compared to the hindlimbs, but with no significant difference between inside and outside limbs [10].

Speed and circle size influence the requirement for centripetal force production, but the point of application of the ground reaction force was only found to move towards the centre of the circle above walking speed [9]. At trot, the point of application of the ground reaction force was reported to move by $19.8 \pm 10 \mathrm{~mm}$, producing a 3-times higher centripetal force, but interestingly the amount of systematic movement asymmetry on the same sized circle was comparable between walk and trot [11]. In another study [12] no significant differences in predicted compared to measured body lean angles were found between trot and canter on two different sized circle. In this study, horses leaned marginally less into the circle than predicted and significant differences in body lean angle between horses and turn directions were found. These studies provide evidence to suggest that centripetal force may not be the primary variable responsible for movement asymmetry on the circle [11].

The effect of exercise on movement symmetry was explored in two different studies. The first used a longitudinal approach, measuring the vertical head (forelimb) and pelvis (hindlimb) movement of trotters that were in training fourteen times from yearlings to 3-year olds. The horses were grouped according to when they qualified to race and it was found that forelimb movement asymmetry was associated with delayed race qualification [13]. The second study compared movement symmetry before and after endurance rides of 120-160 kilometres and found a significant decrease in post-ride symmetry of the trunk [14]. Long term and/or endurance exercise may therefore result in asymmetric musculoskeletal development, which may have a direct influence on performance. Understanding the extrinsic 
and intrinsic factors that leads to asymmetric development during exercise will offer health, welfare and performance benefits.

\section{Equine locomotion and sports performance}

Biomechanical studies of sports horses and race horses sit on one of the two sides of a balancing scale. One side of the scale concerns the health and welfare of the horse, whilst the other side considers performance. The scales must balance if we are to maintain health and welfare without compromising performance. In balancing the scales we must therefore understand the performance demands placed upon the horse and this section describes studies that were presented on aspects of performance.

The most explosive capabilities of galloping horses were highlighted in a study comparing Quarter Horse sprint races to Thoroughbred classic distance stakes races [15]. The average stride rates for Quarter Horses were 25\% greater than for Thoroughbreds (2.88 vs 2.34 strides/sec). When just considering the Thoroughbreds, these stride rates and associated respiratory rates are quite remarkable. The higher values in Quarter Horses reported here may have implications for skeletal and respiratory soundness, although further work is needed to explore the capabilities of these horses. The effects of speed were investigated in more detail in trotters [16]. As speed increased, vertical loading rate increased in both fore and hind limbs. The relationship between speed and peak vertical force was greater in the hindlimbs, although again both increased with speed and as stance duration decreased so did vertical impulse. A greater increase in hindlimb peak force with an increase in speed has not previously been reported and highlights the necessity of performing biomechanical measurements under real training conditions. Changes in limb loading with speed will also influence the combined centre of pressure (COP) location and therefore the pitching moments 
about the centre of mass (COM) [17]. In particular, it was reported that divergence of the COM from the COP creating a vertical force moment arm prior to midstance may aid in accelerating the COM about the hind foot, thereby passively assisting hindlimb propulsion. The control of stability, balance and locomotion efficiency for different breeds in different gaits and at different speeds will develop a better understanding of the limits of capability in the horse.

Jumping was the topic of interest of a number of studies that considered the demands placed upon the horse and jumping technique. Forces measured during jumping confirmed the difference in roles of the leading and trailing forelimbs during landing where the leading forelimb plays a major part in the retardatory (load-absorption) phase, while trailing forelimb is mainly involved in propulsion [18]. Increased lumbosacral and thoracocolumbar flexion during take-off and flight were reported to be associated with altered limb kinematics on landing, which may influence limb loading [19]. Neck, thoracic and lumbar motion influenced subjective grading of the jumping technique, and although higher ratings were only weakly related to longer take off distances [20], the probability of success in free jumping increased with increasing take off distance [21]. Increased velocity was found to reduce free jumping success and increasing the number of jumping efforts decreased take-off and landing distances, and height of the forelimb, withers and croup over the fence [22]. Much work is still needed in this area to fully appreciate the demands on the horse, dependant on capability, discipline, fence type, environmental factors and competition level.

One of the key environmental factors is the surface used in training and competition, and studies relating to surfaces were presented by a number of authors. This included the developments of the surface used for the Olympic Games in 2012 and how important water 
management and sub-surface construction are to achieving functional properties that support elite performance [23]. Rider perception of these properties could be considered as important as the measurement of them, and when questioned in a survey, riders preferred a surface that produced higher peak loads and greater traction values [24]. Although these functional musculoskeletal injury risk.

Several studies focussed on differences between surface types, which provide additional information in relation to the horse-hoof-surface interaction. In a longitudinal study of twoyear-old Thoroughbred racehorses in training, turf and peat moss training surfaces caused an increase in stride length [25]. Using a pressure mat, vertical force and pressure measurements synonymous with damping decreased on a surface covered with $50 \mathrm{~mm}$ of sand/synthetic material, while contact area increased when compared to being covered with a rubber mat. [26]. A new design of instrumented horse shoe was used to explore surface reaction profiles surfaces.

Also concerning different racing surfaces, forelimb hoof accelerations of galloping Thoroughbreds on a dirt surface compared to a synthetic surface with greater shear strength were recorded [28]. Peak dorsopalmar accelerations were $40 \%$ greater during landing on the synthetic surface compared to a dirt surface and the grab phase was $32 \%$ shorter. In another study [29] maximum loading rate on the synthetic surface was reported to be five times greater than the dirt surface, which suggests a notable increase strain on the suspensory apparatus. The findings of these two studies contrast previous findings of trotting horses on 
all-weather waxed and crushed sand surfaces, suggesting that variability within surface category may be large and should be considered in future studies.

Rider interaction with the horse mainly focussed on asymmetry in the rider and the potential effects on performance. Trunk axial rotation, which has previously been reported in riders, was linked to poor shoulder-in dressage scores and was thought to be due to the right hand dominance of the riders tested [30]. Pelvic posture and motion control were the feature of two studies [31,32]. Control of forward flexion and extension motion of the pelvis during standing was measured in riders and this was compared to horse-rider synchronisation during riding [31]. It was suggested that the ability to control pelvic motion may influence horserider harmony. In another study, standing and sitting pelvic asymmetry was found to be prevalent in riders and this was linked to pelvic asymmetry in the horse [32], although the cause and effect relationship is undoubtedly complex and has yet to be substantially evidenced.

\section{The neck, back and pelvis}

Good health of the axial system in the horse is essential for sustaining good performance. Maintaining health in the neck, back and pelvis is however complex, as pathologies in these structures may develop due to primary or secondary causes and neuromuscular activity may be permanently compromised. Our understanding of the structures, pathologies, functional deficits, neuromuscular response and influence of rehabilitation techniques are developing [33-35], but we have much still to learn. Studies presented provided new information on the axial system, but as in-vivo measurement still poses a number of issues the reliability of several measurement techniques were also explored. 
Intrinsic factors that increase the risk of injury and may be performance limiting include morphological differences between horses. In a study exploring the link between sacroiliac joint degeneration and back pain in Thoroughbred racehorses, a relationship between bone formation and surface area of the joint was found, and back pain was associated with obvious gross pathologies [36]. Interestingly, there was no relationship between bodyweight or age and the surface area of the sacroiliac joint. In another study [37] muscle fibre type distribution in $\mathrm{m}$. psoas major and $\mathrm{m}$. longissimus dorsi was found to vary with breed (Quarter Horses versus Arabians). It was suggested that due to muscle fibre type distribution the deep epaxial muscles mm. psoas minor and the diaphragm are most likely to have a postural stabilization role compared to the hindlimb muscles, where type II and IIX were more prevalent. New information on lamella band measurements of the nuchal ligament of foetal foals in different head and neck positions was also presented [38]. This study found lamella band width differences in different postures and suggested that extreme head and neck positions may interfere with normal elastic energy storage in the nuchal ligament during movement.

Manipulation of the head and neck was used in-vivo to investigate skin displacement in the equine neck using radiopaque skin markers from C1 to C6 [39]. Significant differences of up to $44 \pm 14 \mathrm{~mm}$ between control and "nose to carpus” positions were found between actual vertebral position and skin mounted marker positions. In another study assessing soft tissue artefacts, motion of the ilium and sacrum during manual force application to the equine pelvis were compared using bone fixated and skin mounted sensors [40]. A poor correlation was reported suggesting that kinematics during external movement applied to the pelvis cannot be predicted from skin-mounted sensors. Soft tissue artefacts, which include skin sliding and muscle deformation should always be taken into consideration when using skin mounted 
markers or sensors, as the movement of the soft tissues over the underlying bones can be quite pronounced.

The capabilities of diagnostic imaging techniques were explored by several authors. The locations of clinically important structures including the facet joints, spinal cord, cervical nerve roots and intervertebral disks were identified using magnetic resonance imaging (MRI) and compared to contrast-enhanced computerised tomography (CT) imaging in one study [41]. The CT images were able to depict all osseous borders, but MR images were found to be superior for soft tissue structures. There may therefore be limitations in using contrastenhanced CT imaging when accurate diagnosis of cervical disease is required. The ability to measure interspinous spaces using radiographs was presented by investigating $\mathrm{X}$-ray beam angle when imaging the equine back [42]. This study found differences of up to $2 \mathrm{~mm}$ in spacing depending on the beam angle and suggested that this may result in incorrect evaluation of interspinous spaces. Inter and intra-operator reliability and repeatability using ultrasonography compared to MR imaging was investigated in the equine neck, as atrophy and response to physiotherapy could be measured and monitored more cost-effectively using ultrasound. It was suggested that ultrasonography could be used for cross sectional area (CSA) measurement of m. multifidus and $\mathrm{m}$. longus colli in the mid-cervical spine of the horse, as the CSA of both muscles was larger in this region $[43,44]$.

Rehabilitation studies included a novel assessment of electromyographic (EMG) intensity and duration of vastus lateralis and gastrocnemius lateralis when applying an increasing draft load at walk [45]. Intensity and duration of activity was found to increase with increasing load suggesting that a draft load could be utilised for strength training following injury or to improve athletic performance. Water treadmill exercise is already used for rehabilitation 
purposes, but one study investigated the effects of water depth on pelvic movement. A significant increase in vertical displacement of the pelvis was found as water depth increased without an increase in displacement symmetry [46]. New and improved methods of rehabilitation together with intrinsic and extrinsic factors that increase injury risk should continue to be the focus of scientific study, particularly as changes in the musculoskeletal system can occur so rapidly $[47,48]$.

\section{The foot}

The internal and external morphology of the foot are as important today as they have ever been and yet we still know relatively little about factors that influence growth, conformation and function from the foal to the adult horse. This topic was addressed by a number of authors who highlighted differences between foals and adult horses and functional differences between horses, gaits and shoeing practices.

In relation to growth, hoof renewal in Thoroughbred foals was found to occur at twice the speed given for mature horses [49]. In addition, external characteristics including the hoof pastern axis and hoof angle, which are commonly used to assess dorsopalmar conformation in adult horses cannot be used in foals [50]. It was found that the hoof wall integument and distal phalanx were not parallel in foals and the hoof pastern axis and phalangeal axis were not aligned. The cause of the non-alignment was reported to be widening of hoof integument proximodistally and circumferential bone thickening of the distal phalanx.

In relation to function, one study used a high-speed fluoroscopy system to measure angles of the distal interphalangeal joint (DIPJ) and the deep digital flexor tendon (DDFT) around the navicular bone, and the moment arm of the DDFT [51]. Significant differences in the range 
of motion during stance of the DIPJ between gaits, strides and horses were found, which may result in altered stress distribution in the DDFT. In another study the functional consequences of uneven feet in riding horses was explored, where unevenness was best determined by the differences in dorsal hoof wall angle between forefeet [52]. In horses with uneven feet, larger braking force, vertical force, vertical fetlock displacement and overall, a suppler limb spring during loading were found in the flatter foot. The difference in peak vertical force may indicate early, subclinical signs of lameness in the steeper foot, and the differences in function suggest that altered stress patterns within the limb tissues are likely.

With respect to shoeing, Icelandic horses in competition are commonly shod with weighted boots on excessively high and long hooves to enhance the expressiveness and regularity of the tölt. Two studies reported upon the functional consequences of this shoeing practice. Weight, particularly in combination with high and long hooves increased protraction height, but only marginally increased limb peak forces [53]. However, high hooves with long toes may have negative implications for the health of the palmar structures of the distal foot, as the DIPJ moment increased significantly [54] and enhanced inertial forces during the swing phase might stress internal distal limb structures [53].

Foot morphology and function should continue to be a research priority, as shoeing and trimming practices can have such a large influence on soundness in the horse.

\section{References}

1. Hopkins, S. and Pfau, T. (2014), Effect of Side of Handling on Movement Symmetry in Horses. Equine Veterinary Journal, 46: 42. doi: 10.1111/evj.12267_127 
2. Van de Water, E., Oosterlinck, M., Willekens, S. and Pille, F. (2014), The Effect of Perineural Anesthesia and Handler Position on Limb Loading and Hoof Balance of the Vertical Ground Reaction Force in Sound Horses. Equine Veterinary Journal, 46: 50. doi: 10.1111/evj.12267_152

3. Pfau, T., Spicer-Jenkins, C., Smith, R., Bolt, D., Fiske, J. A. and Witte, T. (2014), Optimal Gait Parameters for Quantifying the Effect of Diagnostic Analgesia in Horses. Equine Veterinary Journal, 46: 46. doi: 10.1111/evj.12267_141

4. Weller, R., Love, A., Clark, B., Smith, R. and Pfau, T. (2014), Is There a Relationship between Tail Carriage and Lameness in Horses?. Equine Veterinary Journal, 46: 55. doi: 10.1111/evj.12267_167

5. Chateau, H., Camus, M., Holden-Douilly, L., Lepley, J., Falala, S., Ravary, B., Vergari, C., Denoix, J., Pourcelot, P. and Crevier-Denoix, N. (2014), Kinetics of the Forelimb in Horses Trotting an Uphill and Downhill Slope. Equine Veterinary Journal, 46: 37. doi: 10.1111/evj.12267_113

6. Hammarberg, M., Egenvall, A. and Rhodin, M. (2014), Subjective Evaluation of Lameness in Horses During Lungeing. Equine Veterinary Journal, 46: 41. doi: 10.1111/evj.12267_124

7. Starke, S., May, S. and Pfau, T. (2014), Towards Reliable Objective Lameness Quantification on the Circle. Equine Veterinary Journal, 46: 48. doi: 10.1111/evj.12267_147 
8. Thomsen, M., Sahl-Tjørnholm, C., Sørensen, H. and Tolver, A. (2014), Effect of Lungeing and Circle Size on Movement Symmetry in Sound Riding Horses. Equine Veterinary Journal, 46: 49-50. doi: 10.1111/evj.12267_151 10.1111/evj.12267_132 doi: 10.1111/evj.12267_114

11. Starke, S., Merritt, J., Stubbs, N., Pfau, T. and Clayton, H. (2014), Is Foot Placement Related to Body Movement Asymmetry During Circular Locomotion?. Equine Veterinary Journal, 46: 48-49. doi: 10.1111/evj.12267_148

12. Brocklehurst, C., Weller, R. and Pfau, T. (2014), Effect of Gait and Turn Direction on Body Lean Angle in the Horse. Equine Veterinary Journal, 46: 36-37. doi: 10.1111/evj.12267_111

13. Ringmark, S., Jansson, A. and Roepstorff, L. (2014), Can Locomotion Asymmetry in Young Trotters Predict Early Race Performance?. Equine Veterinary Journal, 46: 47. doi: 10.1111/evj.12267_144 
14. Nissen, A., Andersen, P., Buhl, R. and Thomsen, M. (2014), Changes in Movement Symmetry During Long-Term Exercise in Horses. Equine Veterinary Journal, 46: 54. doi: 10.1111/evj.12267_164

15. Nielsen, B., Robison, C., Fabus, T., Kenny, J. and LeCompte, R. (2014), Stride Rates of Quarter Horses and Thoroughbreds During Races of Short and Classic Race Distances. Equine Veterinary Journal, 46: 44-45. doi: 10.1111/evj.12267_136

16. Crevier-Denoix, N., Camus, M., Pourcelot, P., Pauchard, M., Falala, S., RavaryPlumioen, B., Denoix, J., Desquilbet, L. and Chateau, H. (2014), Effect of Speed on Stride Parameters and Limb Loading: Comparison between Forelimb and Hindlimb at Training Trot on a Firm Surface. Equine Veterinary Journal, 46: 38. doi: 10.1111/evj.12267_115

17. Hobbs, S., Richards, J. and Clayton, H. (2014), The Effect of Centre of Mass Location on Pitching Moments in Trotting Horses. Equine Veterinary Journal, 46: 41. doi: 10.1111/evj.12267_125

18. Crevier-Denoix, N., Camus, M., Falala, S., Martino, J., Pauchard, M., RavaryPlumioen, B., Desquilbet, L., Denoix, J., Chateau, H. and Pourcelot, P. (2014), Comparison of the Loading of Leading and Trailing Forelimbs in Horses at Landing. Equine Veterinary Journal, 46: 38. doi: 10.1111/evj.12267_116 
20. Walker, V., Tranquille, C., Hoekstra, R., Spear, J. and Bronsvoort, M. (2014), Is Subjective Grading of Jumping Technique Related to Measurable Kinematic Parameters During Flight?. Equine Veterinary Journal, 46: 50-51. doi: 10.1111/evj.12267_154

21. Godoi, F., Bergmann, J., Almeida, F., Toral, F. and Miranda, A. (2014), Probability of Jumping Success of Young Brazilian Sport Horses Assessed Via Kinematic Analysis. Equine Veterinary Journal, 46: 40. doi: 10.1111/evj.12267_122

22. Rodrigues, T., Godoi, F., Ramos, M., Andrede, A. and Almeida, F. (2014), Changes in Kinematics During Repeated Jumping. Equine Veterinary Journal, 46: 47-48. doi: 10.1111/evj.12267_145

23. Northrop, A., Martin, J., Blundell, E., Owen, A. and Hobbs, S.J. (2014), Development of the Equestrian Arena Surfaces for the 2012 Olympic Games. Equine Veterinary Journal, 46: 45. doi: 10.1111/evj.12267_137

24. Holt, D., Northrop, A., Martin, J., Daggett, A. and Hobbs, S. (2014), What do Riders Want from an Arena Surface?. Equine Veterinary Journal, 46: 41-42. doi: 10.1111/evj.12267_126 
25. Parkes, R., Pfau, T., Weller, R. and Witte, T. (2014), The Effect of Training on Stride Parameters in a Cohort of 40 Two Year Old Racehorses. Equine Veterinary Journal, 46: 45-46. doi: 10.1111/evj.12267_139

26. Oosterlinck, M., Royaux, E. and Pille, F. (2014), Pressure Plate Evaluation of Forelimb Toe-Heel and Medio-Lateral Hoof Balance on a Hard Versus a Soft Surface in Sound Ponies at the Walk and Trot. Equine Veterinary Journal, 46: 45. doi: 10.1111/evj.12267_138

27. Martin, C., Merritt, J. and Davies, H. (2014), Track Surface Identification Using an Instrumented Horseshoes. Equine Veterinary Journal, 46: 43. doi: 10.1111/evj.12267_130

28. Symons, J., Garcia, T., Soohoo, E. and Stover, S. (2014), Breezing Thoroughbred Hoof Accelerations on Dirt and Synthetic Surfaces. Equine Veterinary Journal, 46: 49. doi: 10.1111/evj.12267_149

29. Thornton, J., Symons, J., Garcia, T. and Stover, S. (2014), Distal Forelimb Kinematics During the Extended Trot of Dressage Horses Ridden on Two Different Arena Surfaces. Equine Veterinary Journal, 46: 49. doi: 10.1111/evj.12267_150

30. Baxter, J., Hobbs, S. and Chohan, A. (2014), Preliminary Assessment of Dressage Asymmetry within Sitting Trot and Shoulder-in. Equine Veterinary Journal, 46: 5. doi: 10.1111/evj.12267_13 
32. Browne, L. and Cunliffe, C. (2014), An Investigation of Relationships between Horse and Rider Pelvic Asymmetry. Equine Veterinary Journal, 46: 37. doi: 10.1111/evj.12267_112

33. Stubbs, N. C., Riggs, C. M., Hodges, P. W., Jeffcott, L. B., Hodgson, D. R., Clayton, H. M. and McGowan, C. M. (2010), Osseous spinal pathology and epaxial muscle ultrasonography in Thoroughbred racehorses. Equine Veterinary Journal, 42: 654661. doi: 10.1111/j.2042-3306.2010.00258.x

34. Stubbs, N.C., Kaiser, L.J., Hautpman, J. and Clayton, H.M. (2011), Dynamic mobilisation exercises increase cross sectional area of multifidus. Equine Veterinary Journal, 43(5):522-9. DOI: 10.1111/j.2042-3306.2010.00322.x

35. Rombach, N. Clayton, H.M. and Stubbs, N.C. (2014), Gross anatomy of the deep perivertebral musculature in horses. American Journal of Veterinary Research, 75(5):433-40. DOI: 10.2460/ajvr.75.5.433

36. Goff, L., Jeffcott, L., Riggs, C. and McGowan, C. (2014), Sacroiliac Joint Morphology: Influence of Age, Bodyweight and Previous Back Pain. Equine Veterinary Journal, 46: 52. doi: 10.1111/evj.12267_159 
37. Hyytiäinen, H., Mykkänen, A., Hielm-Björkman, A., Stubbs, N. and McGowan, C. (2014), Muscle Fibre Type Distribution of the Thoracolumbar and Hindlimb Regions of Horses: Relating Fibre Type and Functional Role. Equine Veterinary Journal, 46: 53. doi: 10.1111/evj.12267_162

38. Nestadt, C. and Davies, H. (2014), Effects of Thoracic Posture on the Nuchal Ligament in Foetal Foals. Equine Veterinary Journal, 46: 44. doi: 10.1111/evj.12267_135

39. Bergh, A., Egenvall, A., Olsson, E., Uhlhorn, M. and Rhodin, M. (2014), Skin Displacement in the Equine Neck. Equine Veterinary Journal, 46: 36. doi: 10.1111/evj.12267_110

40. Goff, L., Van Weeren, P., Jeffcott, L. and McGowan, C. (2014), Measurement of Motion During Manipulation of the Equine Pelvis. Equine Veterinary Journal, 46: 5253. doi: 10.1111/evj.12267_160

41. Sleutjens, J., Cooley, A., Sampson, S., Wijnberg, I., Back, W., van der Kolk, J. and Swiderski, C. (2014), The Equine Cervical Spine: Comparing MRI and ContrastEnhanced CT Images with Anatomic Slices in the Sagittal, Dorsal and Transverse Plane. Equine Veterinary Journal, 46: 48. doi: 10.1111/evj.12267_146

42. Djernæs, J., Vedding Nielsen, J. and Berg, L. (2014), Effect of X-Ray Beam Angle and Superimposition on Radiographic Evaluation of Kissing Spines Syndrome. Equine Veterinary Journal, 46: 39-40. doi: 10.1111/evj.12267_120 
477

478

479

480

481

482

483

484

485

486

487

488

489

490

491

492

493

494

495

496

497

498

43. Rombach, N., Pease, A. and Stubbs, N. (2014), Cross-Sectional Area Measurement of Cervical Spinal Muscles. Equine Veterinary Journal, 46: 54. doi: 10.1111/evj.12267_165

44. Rombach, N. and Stubbs, N. (2014), Intra-Operator and Inter-Operator Reliability and Repeatability of Muscle Measurement Via Ultrasonography in the Equine Cervical Spine. Equine Veterinary Journal, 46: 54-55. doi: 10.1111/evj.12267_166

45. Crook, T., Hodson-Tole, E. and Wilson, A. (2014), Variations in Muscle Activity of Vastus Lateralis and Gastrocnemius Lateralis with Increasing Draft Load. Equine Veterinary Journal, 46: 38-39. doi: 10.1111/evj.12267_117

46. York, J. and Walker, A. (2014), Vertical Displacement of the Equine Pelvis When Trotting on an Aqua Treadmill. Equine Veterinary Journal, 46: 55. doi: 10.1111/evj.12267_168

47. Greve, L. and Dyson, S. (2014), Back-Shape Changes in Sports Horses. Equine Veterinary Journal, 46: 53. doi: 10.1111/evj.12267_161

48. Holmes, J., Mirams, M., Mackie, E. and Whitton, C. (2014), Subchondral Bone Remodelling Is More Active in Resting Than Training Thoroughbred Racehorses. Equine Veterinary Journal, 46: 27-28. doi: 10.1111/evj.12267_83

499 
50. Curtis, S., Martin, J. and Hobbs, S. (2014), External and Radiographic Hoof Angles Differ in Thoroughbred Foals. Equine Veterinary Journal, 46: 39. doi: 10.1111/evj.12267_118

51. Weller, R., Bryars, J., Roach, J. and Pfau, T. (2014), Internal Foot Kinematics Using High-Speed Fluoroscopy. Equine Veterinary Journal, 46: 51-52. doi: 10.1111/evj.12267_157

52. Wiggers, N., Nauwelaerts, S., Bool, S., Hobbs, S. and Back, W. (2014), Biomechanical Consequences of Uneven Forefeet and Hoof Conformation in Riding Horses. Equine Veterinary Journal, 46: 52. doi: 10.1111/evj.12267_158

53. Waldern, N., Wiestner, T., Ramseier, L. and Weishaupt, M. (2014), Effect of Weighted Boots Used with Different Shoeing Styles on Limb Movement and Ground Reaction Forces in Icelandic Horses at Walk, Tölt and Trot. Equine Veterinary Journal, 46: 50. doi: 10.1111/evj.12267_153

54. Weishaupt, M., Waldern, N., Kubli, V. and Wiestner, T. (2014), Effects of Shoeing on Breakover Forces in Icelandic Horses at Walk, Tölt and Trot. Equine Veterinary Journal, 46: 51. doi: 10.1111/evj.12267_156 